Article

\title{
Thermal Failure Propagation in Lithium-Ion Battery Modules with Various Shapes
}

\author{
Dongxu Ouyang ${ }^{1}$, Jiahao Liu ${ }^{2}$, Mingyi Chen ${ }^{3}$, Jingwen Weng ${ }^{4}$ and Jian Wang ${ }^{1, *}$ \\ 1 State Key Laboratory of Fire Science, University of Science and Technology of China, \\ Hefei 230022, China; ouyang11@mail.ustc.edu.cn \\ 2 College of Ocean Science and Engineering, Shanghai Maritime University, \\ Shanghai 201306, China; jiahao@shmtu.edu.cn \\ 3 School of Environment and Safety Engineering, Jiangsu University, \\ Zhenjiang 212013, China; chenmy@ujs.edu.cn \\ 4 School of Environment and Resources, Fuzhou University, Fuzhou 350116, China; 061400237@fzu.edu.cn \\ * Correspondence: wangj@ustc.edu.cn
}

Received: 7 July 2018; Accepted: 26 July 2018; Published: 31 July 2018

check for updates

\begin{abstract}
Thermal failure propagation is one of the most severe challenges for battery modules and it usually aggravates the thermal hazards, further resulting in serious accidents. This work conducted two groups of experiments to investigate the influence of discharging treatment and module shape on the thermal failure propagation of battery modules, where the triangle module, rectangle module, parallelogram module, line module, hexagon module, and square module were researched. Based on the results, it can be found that an evident domino effect existed on the thermal failure propagation of battery modules. Namely, the failure propagation process consisted of several phases and the number of phases depended on the shape of the module. Besides, it is indicated that discharging treatment on a battery module when it was in a high-temperature environment would aggravate its thermal failure propagation by bringing an earlier thermal failure, a quicker failure propagation, and a larger mass loss. Combining the results of safety and space utilization, it is revealed that the triangular module may be the best choice of battery module due to its smaller failure propagation speed and higher space utilization.
\end{abstract}

Keywords: battery module; thermal failure propagation; discharging treatment; module shape; surface temperature; mass loss

\section{Introduction}

As one of the most promising power sources, lithium-ion batteries (LIBs) have been widely used, ranging from consumer electronic devices to electric vehicles due to their excellent properties, such as good stability, high voltage, low self-discharge rate, high energy density, long life cycle, etc. [1,2]. Nevertheless, hazards also arise from fire or explosion accidents of LIBs, which frequently result from the sensitivities of LIBs to abusive conditions, including high temperature, crushing, overcharge, over-discharge, short-circuit, etc. [3-5]. Especially in battery modules where quantities of batteries are connected together to provide power, the hazards will be greatly aggravated. Once out of control, the failure of some batteries will propagate to the surrounding ones and lead to rigorous consequences. The battery modules in the several accidents of electrical vehicles (EVs) reported recently all caught fire fire and resulted in serious outcomes. Thence, the safety issues of LIBs, and especially the thermal failure propagation in battery modules and the management of battery modules, cannot be overemphasized.

So far, considerable research efforts have been directed toward the thermal behaviors of LIBs under high-temperature conditions [6-12]. Ribière et al. investigated the fire-induced hazards of LIBs 
by fire calorimetry and analyzed the toxicity of gases generated, including $\mathrm{CO}, \mathrm{CO}_{2}, \mathrm{SO}_{2}$, and $\mathrm{HF}$. It was observed that the production of these gases mainly depended on the battery state of charge (SOC). Larsson et al. took six fire abuse tests to evaluate the heat release rate and HF emissions of commercial LIBs. They found that LIBs exposed to a fire were significantly more reactive at $100 \%$ SOC than that at lower SOCs, and energetic outbursts were observed during tests. Liu et al. employed a technique, Copper Slug Battery Calorimetry (CSBC), to investigate a widely used LIB at various SOCs. It was shown that the total energy generated inside the battery increased with increasing SOC.

Additionally, more work concerned the management of battery modules which can be summarized as several types, such as air, liquid, and phase change material (PCM) based systems [13-19]. Saw et al. conducted a numerical simulation to analyze the air cooling of a battery module and the results demonstrated that an increase of cooling air flow rate could result in the increase of heat transfer coefficient and pressure drop. Huo et al. designed a minichannel, cold-plate-based battery thermal management system to investigate the effects of number of channels, flow direction, inlet mass flow rate, and ambient temperature on temperature rise and distribution of the battery. They found that the maximum temperature of the battery decreased with increasing number of channels and inlet mass flow rate. Besides that, Yan et al. investigated the thermal performance of PCM-based battery thermal management systems in dynamic cycling, and identified several factors influencing the PCM system. Results showed that the cooling performance of the PCM system was superior to that of the natural convection system, especially at a high current rate, and they recommended the PCM with a phase change temperature of $45^{\circ} \mathrm{C}$ to be used in the real battery pack system.

Moreover, many scholars performed experiments or simulations to probe the thermal runaway propagation in LIB modules [20-27]. Feng et al. established a 3D thermal runaway propagation model for a large-format LIB module based on energy balance equation. They proposed that the thermal runaway propagation could be postponed or prevented by increasing the thermal runaway triggering temperature, reducing the total electric energy released during thermal runaway, enhancing the heat dissipation level by increasing the convection coefficient, and adding an extra thermal regulation layer between adjacent batteries. Lamb et al. examined the failure propagation behaviors of small modules of cylindrical and stacked pouch cells after thermal runaway was induced in a single cell. Cylindrical cells were observed to be less prone to propagate compared to the pouch cells, owing to the limited contact between neighboring cells. Coman et al. presented a numerical model to analyze the heat propagation in a custom-made battery module. It was found that a combination of small insulating layers wrapped around the cells and a conductive heat sink was beneficial to design a safer battery module which could mitigate the thermal runaway propagation.

However, many accidents of LIBs take place when they are in the state of usage, such as EVs catching fire when they are running and laptops catching fire during use. But little research has been done to investigate the thermal failure propagation of battery modules under discharging condition, and differences between modules with or without discharging have not been a concern. In addition, battery modules are generally arranged in various shapes according to the application scenarios, while the characteristics of thermal failure propagation in modules with different shapes still lack examination. Thus, this paper conducted an experimental study on the thermal failure propagation in battery modules, intended for revealing the effects of discharging and module shape on the failure propagation. Specific information, including experimental photograph, battery surface temperature, thermal runaway time, propagation speed, and mass loss, was measured and analyzed to provide necessary basic data for the thermal failure propagation issues of battery modules. 


\section{Experiment}

\subsection{Materials}

The battery samples used in this work were cylindrical Samsung 18650-13L (Samsung, Seoul, South Korea) with a capacity of $1300 \mathrm{mAh}$. Their cut-off voltage for charge was $3.7 \mathrm{~V}$ and that for discharge was $2.5 \mathrm{~V}$. Before tests, the original energy stored in the batteries was released by discharging with a CC of $2600 \mathrm{~mA}$ until the voltage decreased to $2.5 \mathrm{~V}$, and then the batteries were charged by the same CC to $75 \%$ SOC. Hereafter, the batteries were placed still for $24 \mathrm{~h}$ to ensure the batteries remained stable before tests. In addition, some common devices in the battery module, such as electronics, BMS, thermal management units, etc., were not involved in this work. Therefore, the battery pack issue analyzed in this paper was a first approximation.

\subsection{Apparatuses and Experimental Design}

The schematic of experimental setup in this work is shown in Figure 1. Battery modules were placed vertically upon a supporting mesh made of iron wire in tests. A K-type thermocouple with a diameter of $1 \mathrm{~mm}$ was attached to the middle of each battery to measure its surface temperature and the temperature was recorded at the data acquisition equipment NI cDAQ-9174 (NI, Austin, TX, USA)) by a computer. The detailed arrangements and numbering of thermocouples are presented in Figure 2. The mass loss data was measured by an electronic balance Mettler Toledo XP10002S (Mettler, Zurich, Switzerland) with a resolution of $0.01 \mathrm{~g}$ and a maximum range of $9 \mathrm{~kg}$. Discharging treatment was achieved by a charge/discharge cycle equipment NEWARE CT-3008 (NEWARE, Shenzhen, China) with a parameter of $5 \mathrm{~V} / 6 \mathrm{~A}$. Additionally, a cylindrical heater with a diameter of $18 \mathrm{~mm}$, a height of $65 \mathrm{~mm}$, and a power of $250 \mathrm{~W}$ was regarded as a thermally failed battery in the module to heat the other batteries. As shown in Figure 3, it was the typical temperature curve of the heater after powering on where the temperature increased at a rate of $4.25^{\circ} \mathrm{C} / \mathrm{s}$ firstly, and then the temperature rising rate declined gradually. Finally, it stabilized at $670{ }^{\circ} \mathrm{C}$. The combustion gases in tests were extracted from the room with the help of an exhaust pump.

Two groups of experiments were carried out to explore the influence of discharging treatment on the thermal failure propagation in battery modules with various shapes, including triangle, rectangle, parallelogram, line, hexagon, and square, where the batteries in modules were connected in parallel and the discharge rate for a single battery was $0.5 \mathrm{C}$. Discharging treatment would finish when the battery module failed. In each module, the heater was displaced in the corner. The detailed experiment configurations are further displayed in Figure 2 and Table 1.

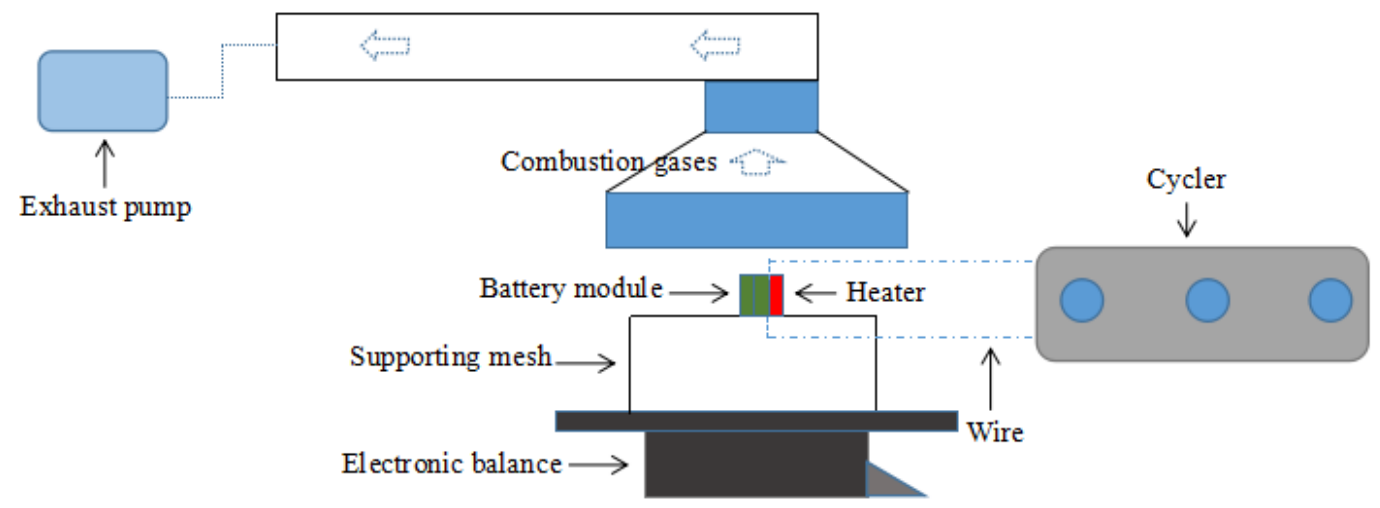

Figure 1. Schematic of the experimental setup. 


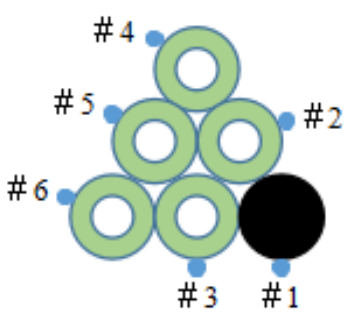

The triangle

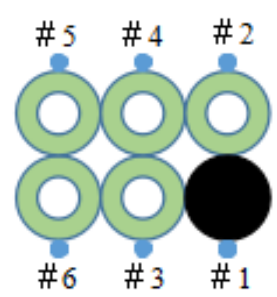

The rectangle

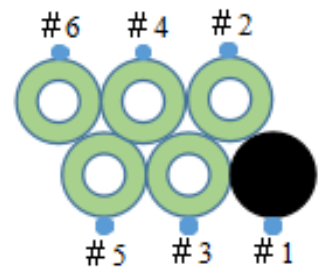

The parallelogram

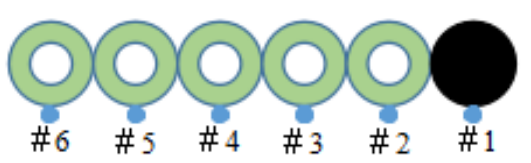

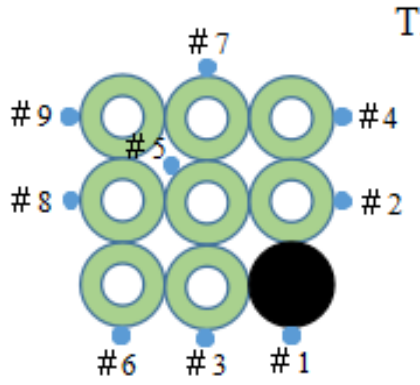

The square

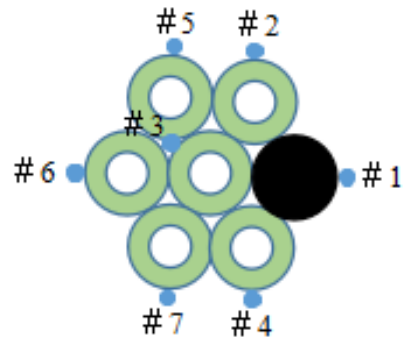

The hexagon
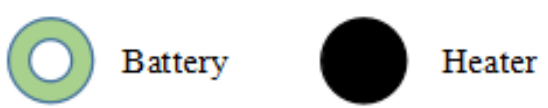

- Thermocouple

Figure 2. Schematic of battery modules and thermocouple arrangements from the top view.

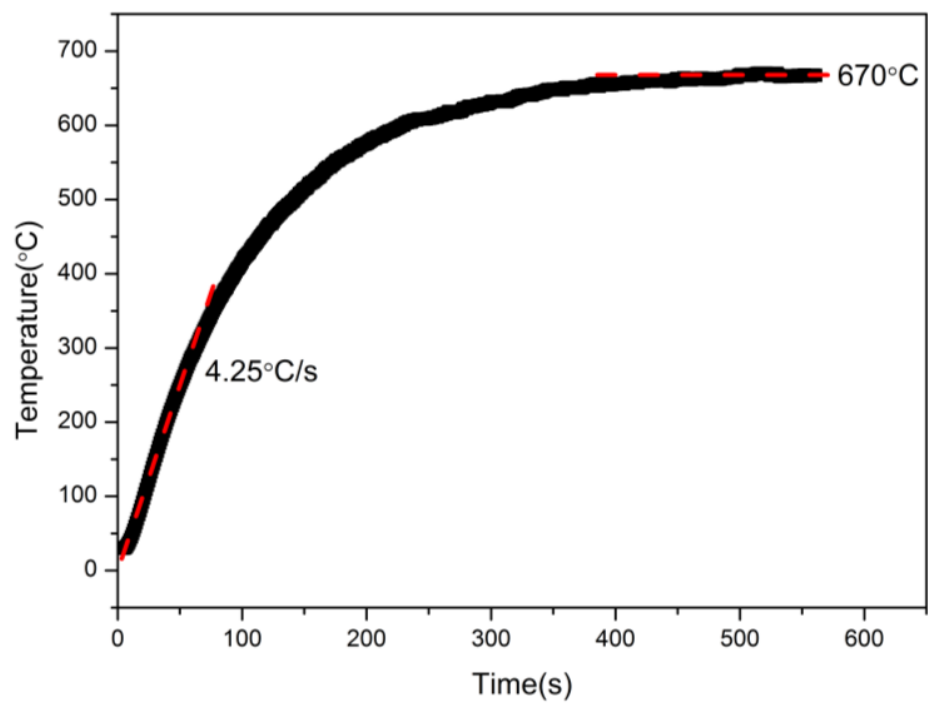

Figure 3. The temperature curve of the heater after powered on. 
Table 1. The experimental configurations.

\begin{tabular}{|c|c|c|c|c|}
\hline Group No. & Test No. & Module Shape & SOC & With Discharging Treatment \\
\hline \multirow{6}{*}{1} & 1 & triangle & \multirow{12}{*}{$75 \%$} & \multirow{6}{*}{ Yes } \\
\hline & 2 & rectangle & & \\
\hline & 3 & parallelogram & & \\
\hline & 4 & line & & \\
\hline & 5 & hexagon & & \\
\hline & 6 & square & & \\
\hline \multirow{6}{*}{2} & 1 & triangle & & \multirow{6}{*}{ No } \\
\hline & 2 & rectangle & & \\
\hline & 3 & parallelogram & & \\
\hline & 4 & line & & \\
\hline & 5 & hexagon & & \\
\hline & 6 & square & & \\
\hline
\end{tabular}

\section{Results and Discussion}

\subsection{Triangle Module}

The typical surface temperature curves of batteries in triangular modules were plotted in Figure 4. Generally, the thermal failure process of LIBs could be divided into several representative stages: (a) heating stage, (b) gases releasing stage, and (c) thermal runaway stage. At the heating stage, the surface temperature of the batteries rose stably under the effect of the heater. With the continuous growth of temperature, the chemical reactions inside the batteries occurred, accompanied by the generation of numerous gases and heat. The inner pressure of the batteries increased rapidly, leading to the opening of the safety vent. Hereafter, the batteries entered the gases releasing stage, where a large amount of combustible gases were released and the battery temperature increased unceasingly. When the inner temperature and pressure approached the critics, the thermal runaway of the batteries happened with large quantities of gases ejected from the batteries. The combustible gases premixed with air and were further ignited by the external high temperature, resulting in continuous combustion. Subsequently, it could be observed that the surface temperature had a sharp increase to the peak in the range of 500-600 ${ }^{\circ} \mathrm{C}$. Between the gases releasing and the thermal runaway, there existed an interval which could be utilized to escape or take measures to prevent the deterioration to failure. Finally, the combustion extinguished with the consumption of combustibles and the surface temperature declined gradually. In addition, the photographs of packs after tests are also presented in Figure 4. It could be seen that the plastic shell of the batteries was entirely burned away after tests and there were some electrolyte residuals on the surface of the batteries. Besides, it was clear that the positive pole of the batteries was carbonized totally. The nickel belts joining the batteries were ripped because of the violent ejection.

For the thermal failure propagation in the triangular module, an evident domino effect could be observed, and the two phases of thermal failure were demonstrated. For dominoes, where the collapse of the previous card would lead to the collapse of the next one, the thermal failure in battery modules also exhibited a similar phenomenon. The two batteries close to the heater appeared to release gases at first and then took thermal failure at about $344 \mathrm{~s}$. The thermal failure of the first phase caused an accelerated temperature rise of the batteries in the second phase. Hereafter, their gases releasing emerged and the thermal failure took place at around $555 \mathrm{~s}$. Namely, the thermal failure propagated from the first phase to the second phase. From the heater to the second phase of batteries, the propagation distance could be estimated by the geometry (i.e., $\sqrt{3} \mathrm{~d}$ ), as shown in Figure 5 . Therefore, the propagation speed could be calculated as $0.056 \mathrm{~mm} / \mathrm{s}$.

On the other hand, Figure $4 a, b$ reveals the surface temperature curves of batteries in modules with and without discharging treatment. After comparing, it can be found that the thermal failure propagation in the battery module with discharging treatment was worse than that without discharging 
treatment. For the latter, its thermal failure corresponding to the first and second phases appeared at $387 \mathrm{~s}$ and $575 \mathrm{~s}$, respectively. Both of them were more hysteretic than that of the former. Correspondingly, the propagation speed was $0.054 \mathrm{~mm} / \mathrm{s}$. It indicated that discharging treatment would aggravate the thermal failure propagation of the battery module. This might be attributed to the more positive materials inside the battery under discharging so that it was easier to react with each other and took thermal failure [28].

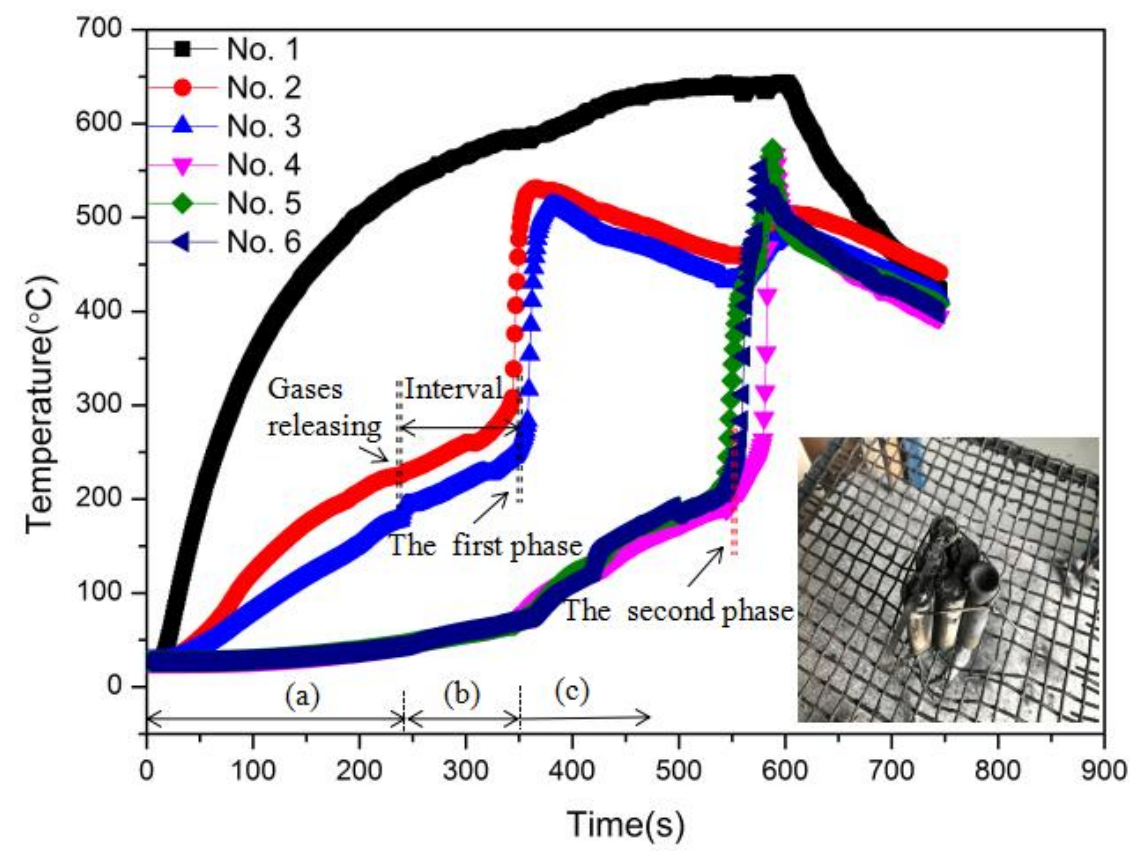

(a)

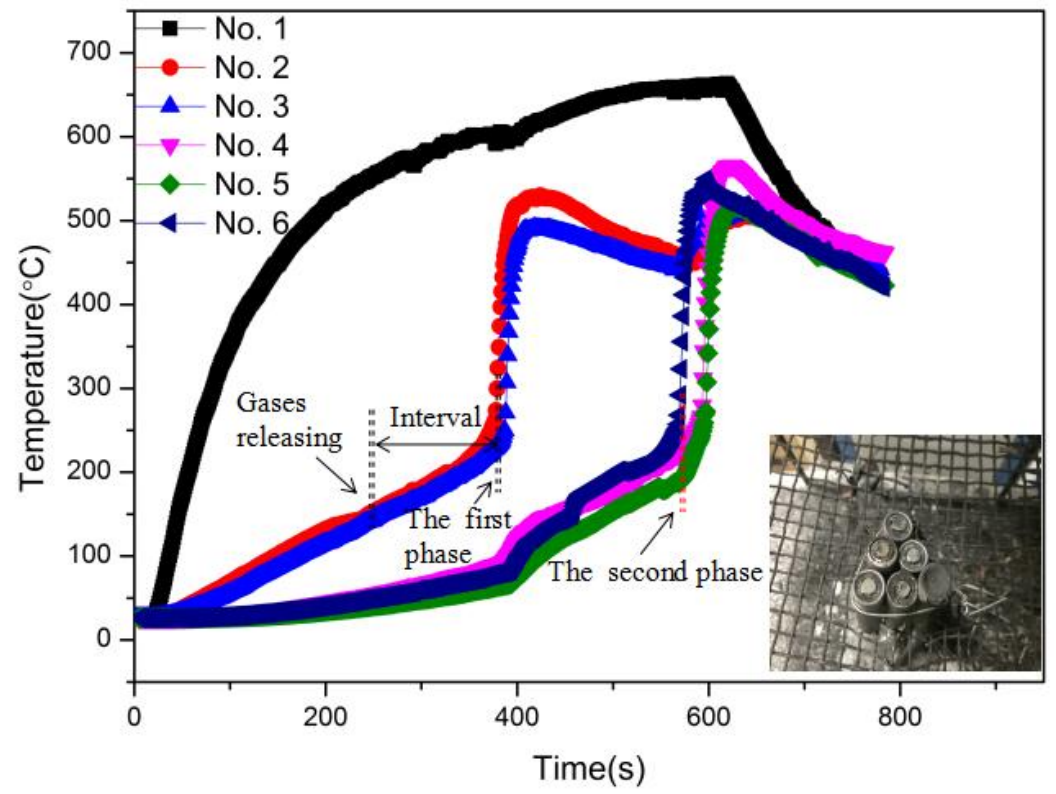

(b)

Figure 4. The typical surface temperature curves of batteries in triangular modules: (a) with discharging treatment; (b) without discharging treatment.

Finally, Figure 6 presents the typical curves of mass loss for the triangular modules in the tests. As discussed above, the several typical stages during the thermal failure propagation of modules could 
also be observed in the mass curves. At the heating stage, the mass changed slightly. When it started to release gases, the mass decreased gradually, followed by the mass exhibiting an obvious drop as the thermal runaway appeared. It was clear that there existed two evident mass losses in the curve which corresponded to the two phases of thermal failure. Additionally, it can be found that there were some rebound points in the mass curves which were the results of gases releasing and thermal runaway. When gases were released or thermal runaway appeared, the high speed gas lease could produce a positive pulse to the balance. Besides that, it was shown that the battery module had a total mass loss of $51.0 \mathrm{~g}$ and $50.1 \mathrm{~g}$, corresponding to the modules with and without discharging treatment, respectively. This result indicated that the module with discharging treatment underwent a relatively more obvious mass loss which resulted from the worse thermal behavior in failure propagation of the discharged module. In summary, discharging treatment worsened the thermal failure propagation of the battery module, including the earlier thermal failure, the quicker failure propagation, and the larger mass loss, which revealed that the battery module in work would possess higher thermal hazards. The detailed information is further listed in Table 2.

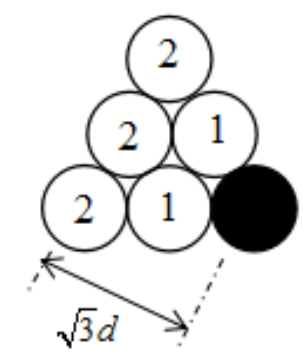

Figure 5. The domino effect of thermal failure propagation in triangular module.

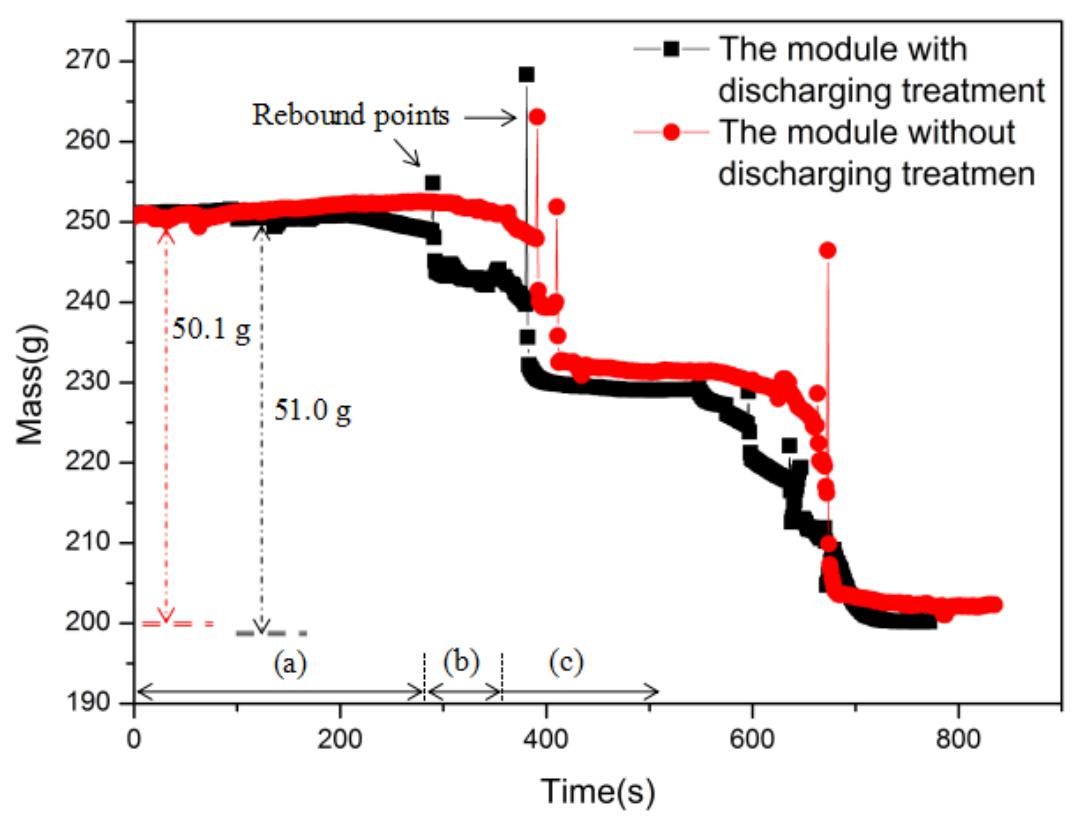

Figure 6. The typical curves of mass loss for triangular modules.

Table 2. The detailed information of triangular modules.

\begin{tabular}{cccccc}
\hline No. & $\begin{array}{c}\text { With Discharging } \\
\text { Treatment }\end{array}$ & $\begin{array}{c}\text { Time to the } \\
\text { First Phase (s) }\end{array}$ & $\begin{array}{c}\text { Time to the } \\
\text { Second Phase (s) }\end{array}$ & $\begin{array}{c}\text { Propagation } \\
\text { Speed (mm/s) }\end{array}$ & Mass Loss (g) \\
\hline 1 & Yes & 344 & 555 & 0.056 & 51.0 \\
2 & No & 387 & 575 & 0.054 & 50.1 \\
\hline
\end{tabular}




\subsection{Rectangle Module}

Figure 7 shows the typical surface temperature curves of batteries in rectangular modules during tests. Similarly, the domino effect in the failure propagation of rectangular modules could be observed and it consisted of three phases, further illustrated in Figure 8. For the thermal failure propagation in rectangular modules with discharging treatment, the two batteries near the heater failed firstly at about $368 \mathrm{~s}$ which formed the first phase of failure, then it propagated to the battery in the middle at around $440 \mathrm{~s}$. Finally, in the third phase, the two batteries farthest away from the heater took failure at about $568 \mathrm{~s}$. In rectangular modules, the propagation distance of failure was two times the battery diameter, $36 \mathrm{~mm}$. Thence, the propagation speed could be calculated as $0.063 \mathrm{~mm} / \mathrm{s}$. In addition, it could be seen that the three phases of failure for the rectangular module without discharging treatment appeared at 389 s, 480 s, and 583 s, respectively, in Figure 7b. All of them lagged behind the failure in modules with discharging treatment, and the propagation speed was $0.062 \mathrm{~mm} / \mathrm{s}$. Similar to the results in Section 3.1, the discharging treatment aggravated the thermal failure propagation in rectangular modules.

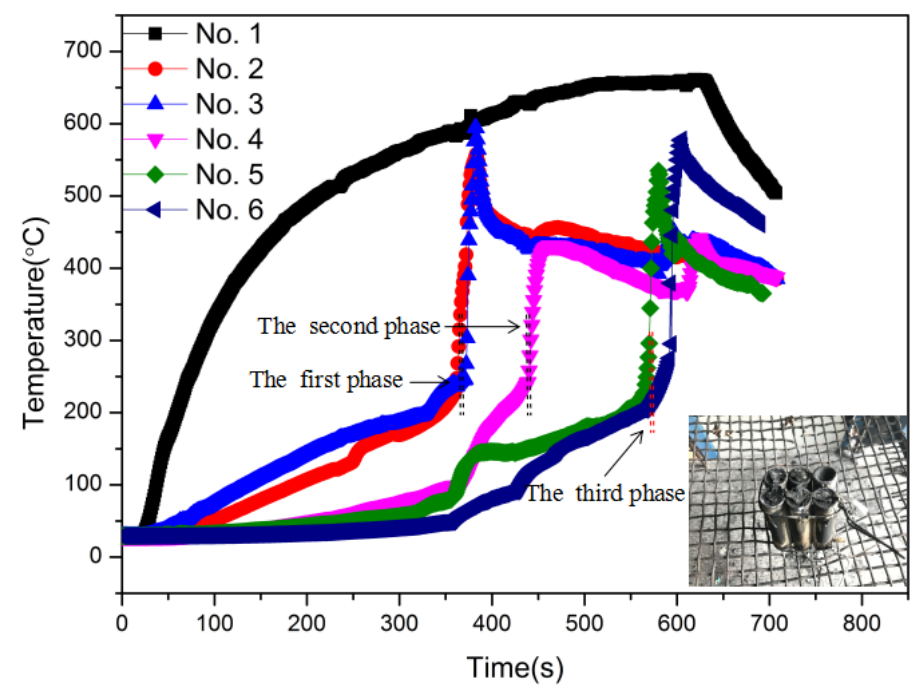

(a)

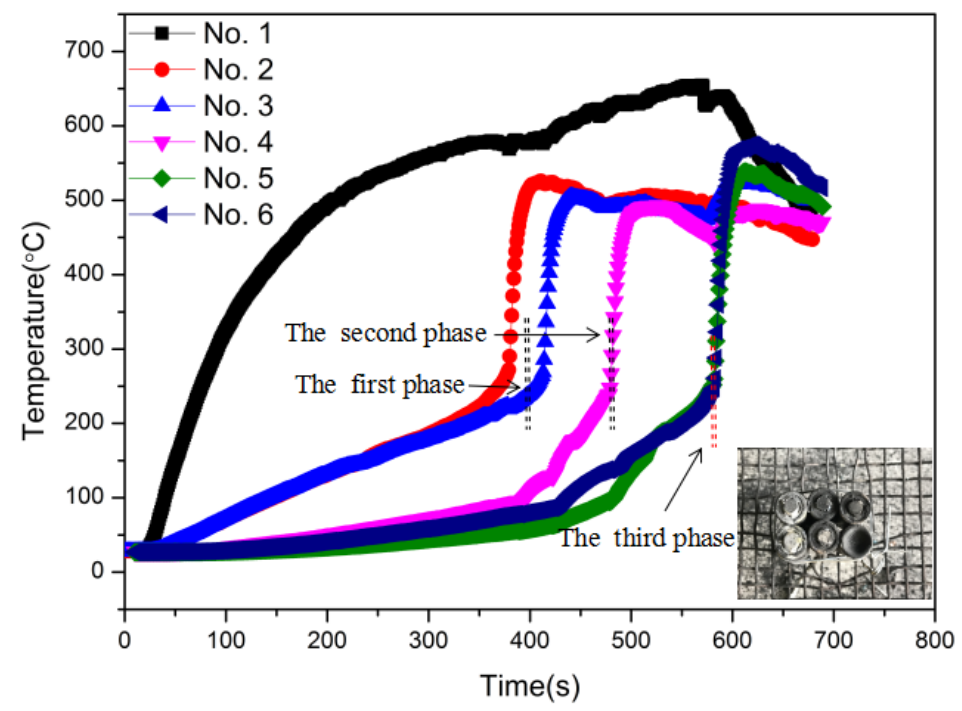

(b)

Figure 7. The typical surface temperature curves of batteries in rectangular modules: (a) with discharging treatment; (b) without discharging treatment. 
Besides that, the typical curves of mass loss for rectangular modules in tests are presented in Figure 9, where there existed three obvious mass loss processes in the curve, which corresponded to the three phases of failure. The mass of modules with discharging treatment declined at first due to the earlier thermal failure. It had a larger mass loss of $51.6 \mathrm{~g}$ compared to that of the module without discharging treatment, which was $50.2 \mathrm{~g}$. The detailed information is further listed in Table 3.

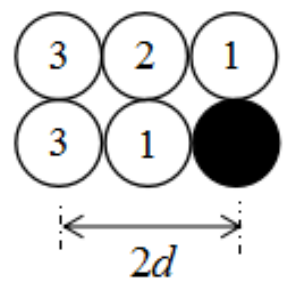

Figure 8. The domino effect of thermal failure propagation in rectangular module.

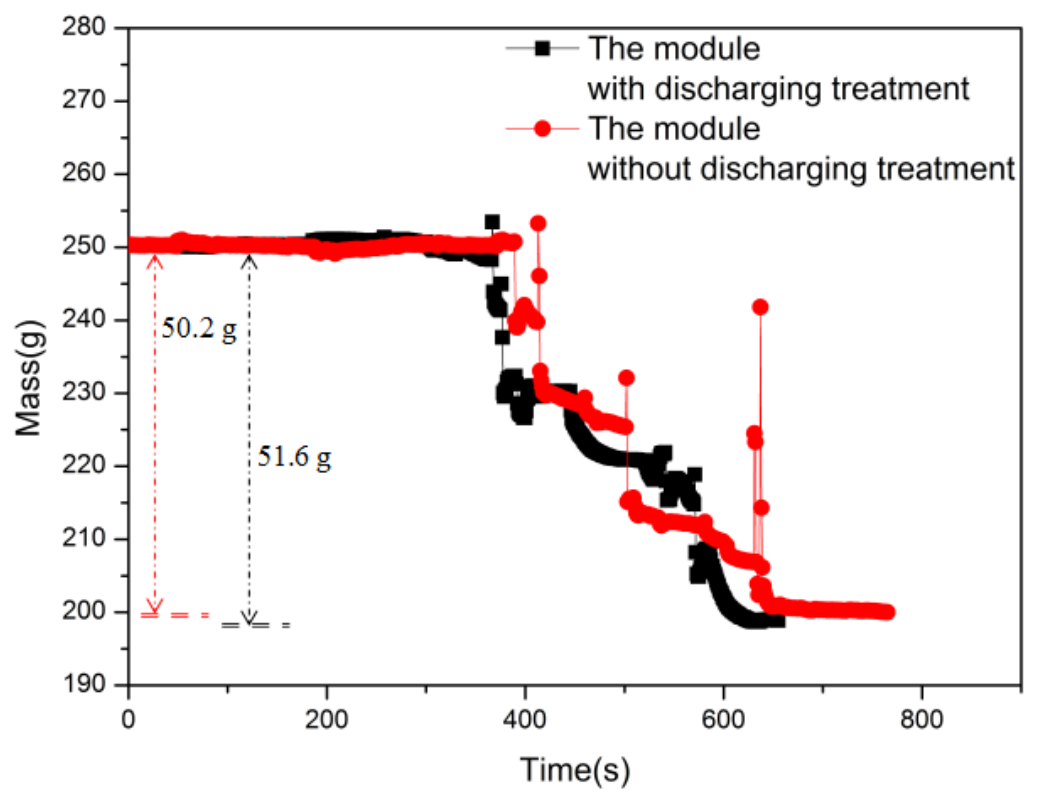

Figure 9. The typical curves of mass loss for rectangular modules in tests.

Table 3. The detailed information of rectangular modules in tests.

\begin{tabular}{ccccccc}
\hline No. & $\begin{array}{c}\text { With Discharging } \\
\text { Treatment }\end{array}$ & $\begin{array}{c}\text { Time to the } \\
\text { First Phase (s) }\end{array}$ & $\begin{array}{c}\text { Time to the } \\
\text { Second Phase (s) }\end{array}$ & $\begin{array}{c}\text { Time to the } \\
\text { Third Phase (s) }\end{array}$ & $\begin{array}{c}\text { Propagation } \\
\text { Speed (mm/s) }\end{array}$ & Mass Loss (g) \\
\hline 1 & Yes & 368 & 440 & 568 & 0.063 & 51.6 \\
2 & No & 389 & 480 & 583 & 0.062 & 50.2 \\
\hline
\end{tabular}

\subsection{Parallelogram Module}

Following, the typical surface temperature curves of batteries in parallelogram modules are shown in Figure 10. Similar to the results of rectangular modules, the thermal failure propagation in parallelogram modules also exhibited three phases. As displayed in Figure 11, the two batteries nearest the heater took failure at first, then the other two batteries failed and the battery in the corner caught fire in the end. For the module with discharging treatment, the time to the three phases of failure were $377 \mathrm{~s}, 533 \mathrm{~s}$, and $626 \mathrm{~s}$, respectively. As for the module without discharging treatment, they were $399 \mathrm{~s}, 554 \mathrm{~s}$, and $651 \mathrm{~s}$, respectively. From the heater to the battery of the third phase, the propagation distance was $46.8 \mathrm{~mm}$. Hence, the propagation speed was $0.075 \mathrm{~mm} / \mathrm{s}$ and $0.072 \mathrm{~mm} / \mathrm{s}$, respectively. Apparently, the thermal failure propagation in modules with discharging treatment was relatively 
faster. In addition, Figure 12 shows the mass loss process of parallelogram modules and the detailed information of failure propagation in parallelogram modules is listed Table 4.

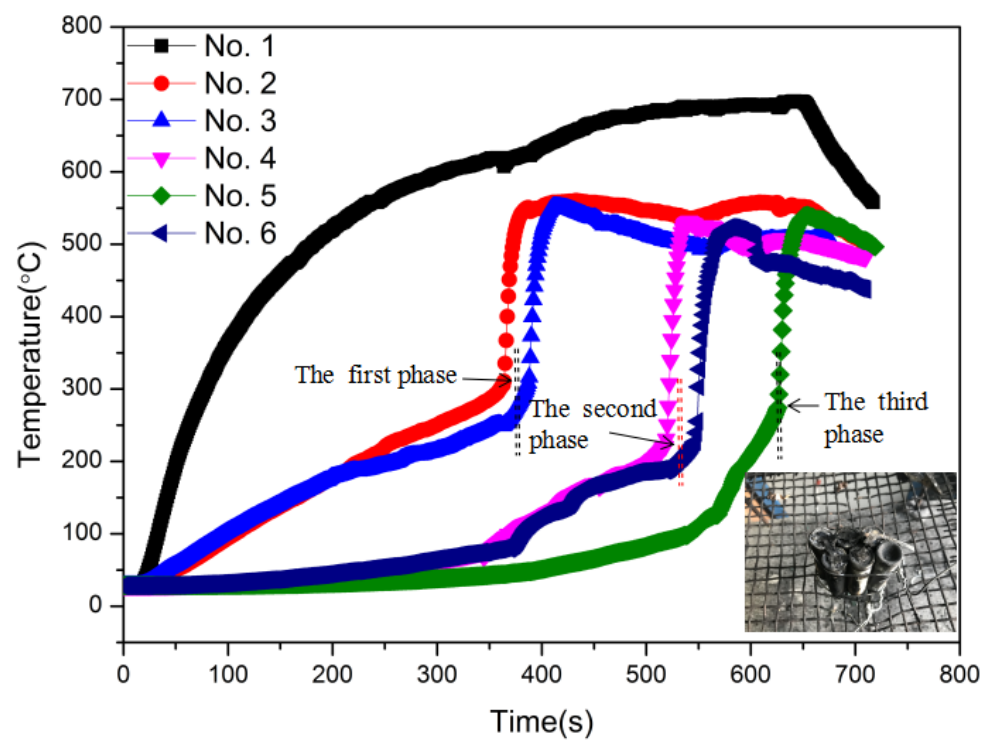

(a)

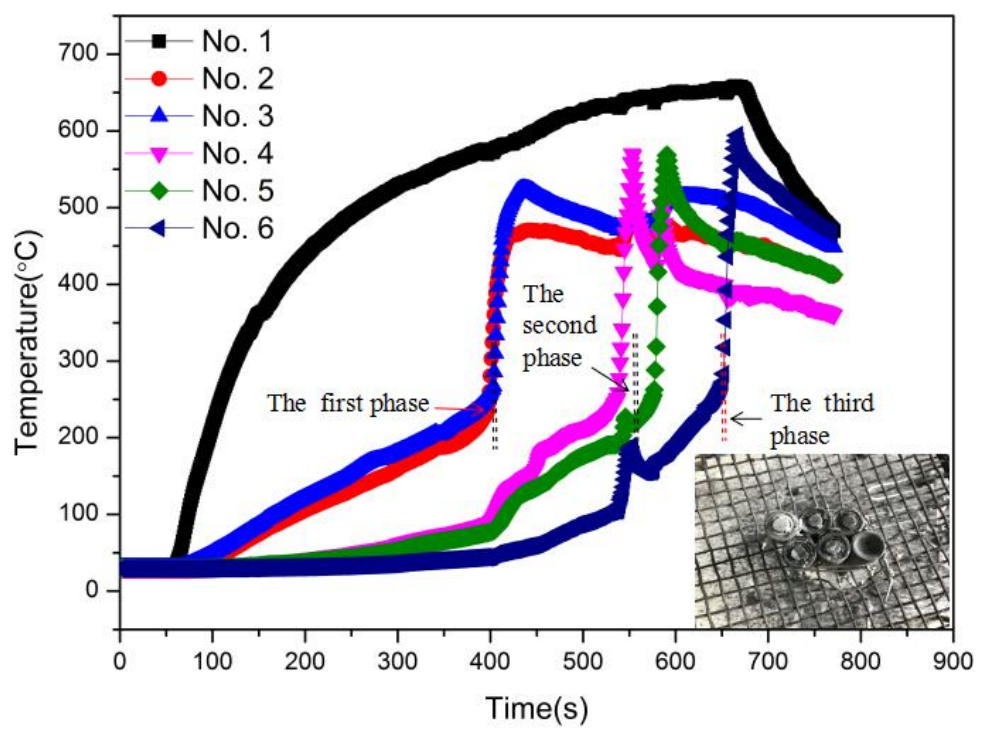

(b)

Figure 10. The typical surface temperature curves of batteries in parallelogram modules: (a) with discharging treatment; (b) without discharging treatment.

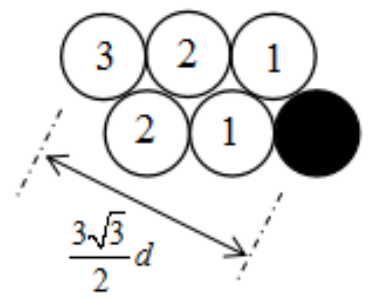

Figure 11. The domino effect of thermal failure propagation in parallelogram module. 


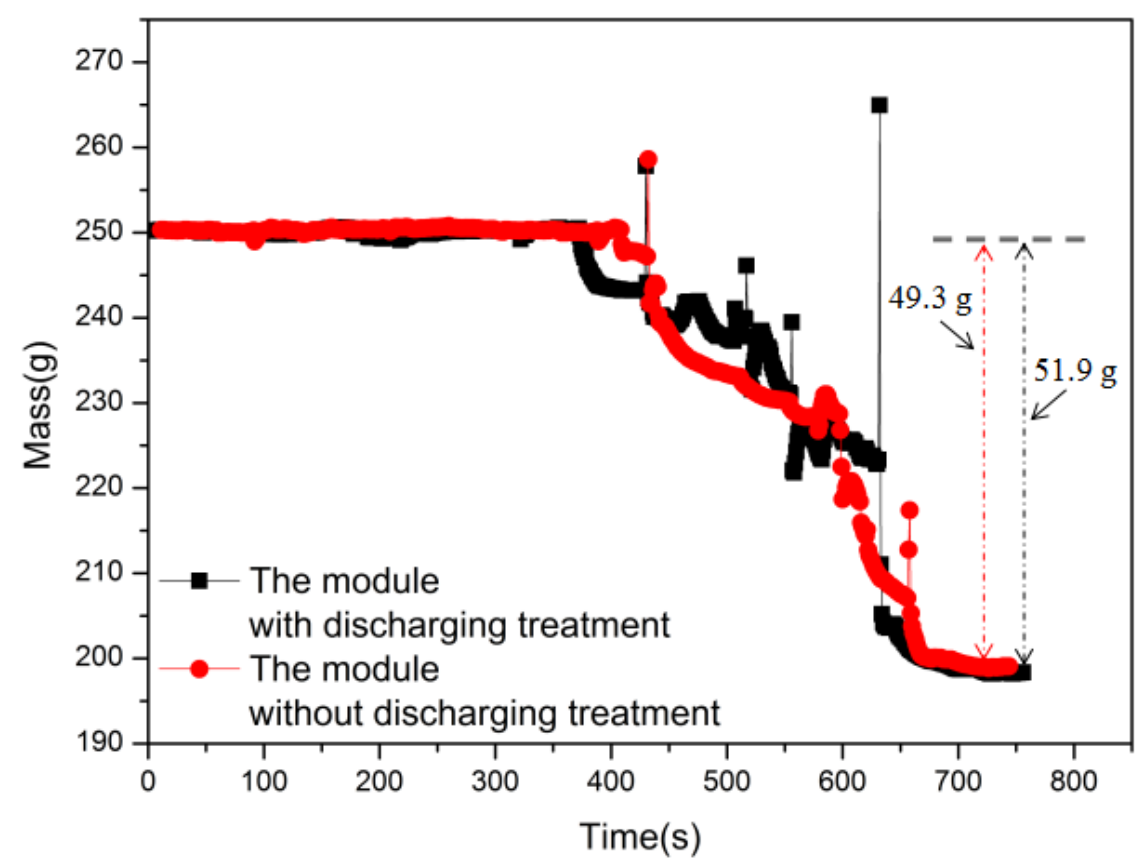

Figure 12. The typical curves of mass loss for parallelogram modules.

Table 4. The detailed information of parallelogram modules.

\begin{tabular}{ccccccc}
\hline No. & $\begin{array}{c}\text { With Discharging } \\
\text { Treatment }\end{array}$ & $\begin{array}{c}\text { Time to the } \\
\text { First Phase (s) }\end{array}$ & $\begin{array}{c}\text { Time to the } \\
\text { Second Phase (s) }\end{array}$ & $\begin{array}{c}\text { Time to the } \\
\text { Third Phase (s) }\end{array}$ & $\begin{array}{c}\text { Propagation } \\
\text { Speed (mm/s) }\end{array}$ & Mass Loss (g) \\
\hline 1 & Yes & 377 & 533 & 626 & 0.075 & 51.9 \\
2 & No & 399 & 554 & 651 & 0.072 & 49.3 \\
\hline
\end{tabular}

\subsection{Linear Module}

Figure 13 shows the surface temperature curves of batteries in linear modules. Different from the results above, only the two batteries close to the heater took thermal failure during tests. This was due to the smaller contact area between batteries in the linear module and the longer distance from the heater. Different from the other modules, there was only one battery in each phase of the linear module which restricted the heat propagation. As revealed in Figure 14, the two batteries near the heater were destroyed severely and their plastic shells had been entirely burned away. It was the result of thermal failure which caused the violent ejection and combustion. As for the battery in the middle, its breakage was not as serious as the two batteries above, which was because the battery only had gases releasing instead of thermal runaway. The heat propagated to it was not enough to support its thermal runaway, although it could be observed that there were some electrolyte residuals in the positive pole which were ejected from the battery. From Figure 13, it is revealed that the two phases of thermal failure in the linear module with discharging treatment took place at $372 \mathrm{~s}$ and $681 \mathrm{~s}$, respectively. As for the module without discharging treatment, the times were $385 \mathrm{~s}$ and $777 \mathrm{~s}$, respectively. For both of them, the surface temperature of the battery in the middle rose obviously after the thermal runaway of the second battery and it stabilized at approximately $180^{\circ} \mathrm{C}$. Not only the heat propagated to it, but also the heat generated inside the battery were insufficient to increase the temperature further. Therefore, the battery stayed at the thermal equilibrium. After observing for $250 \mathrm{~s}$, the heater was turned off and the battery temperature declined subsequently. Regarding the remaining two batteries, their temperatures did not have huge change. In linear modules, thermal failure propagated furthest to the second battery with a propagation distance of $36 \mathrm{~mm}$, which is further listed in Figure 15 . Therefore, the propagation speed was $0.053 \mathrm{~mm} / \mathrm{s}$ and $0.046 \mathrm{~mm} / \mathrm{s}$, corresponding to the two modules, 
respectively. Obviously, the thermal failure propagation in the linear module was relatively slower than in the other shapes, especially for the linear module without discharging treatment.

Besides, the typical curves of mass loss for linear modules in tests are presented in Figure 16. Compared to the others, the linear modules exhibited much slighter mass losses of $26.0 \mathrm{~g}$ and $22.3 \mathrm{~g}$, corresponding to the two linear modules with and without discharging treatment, respectively. The specifics are listed in Table 5.

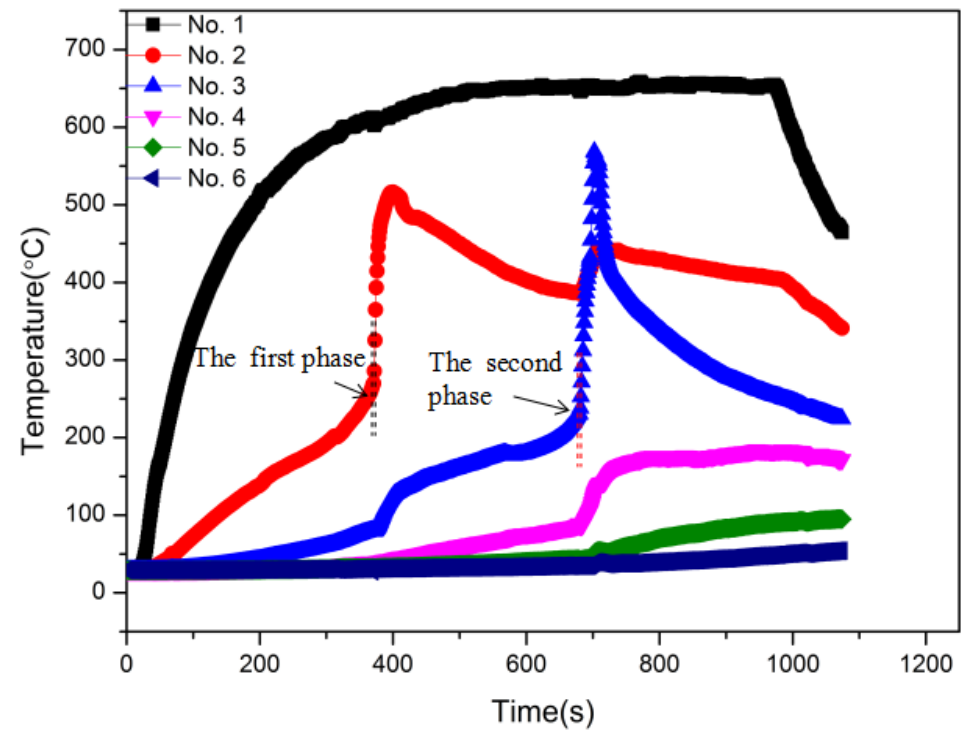

(a)

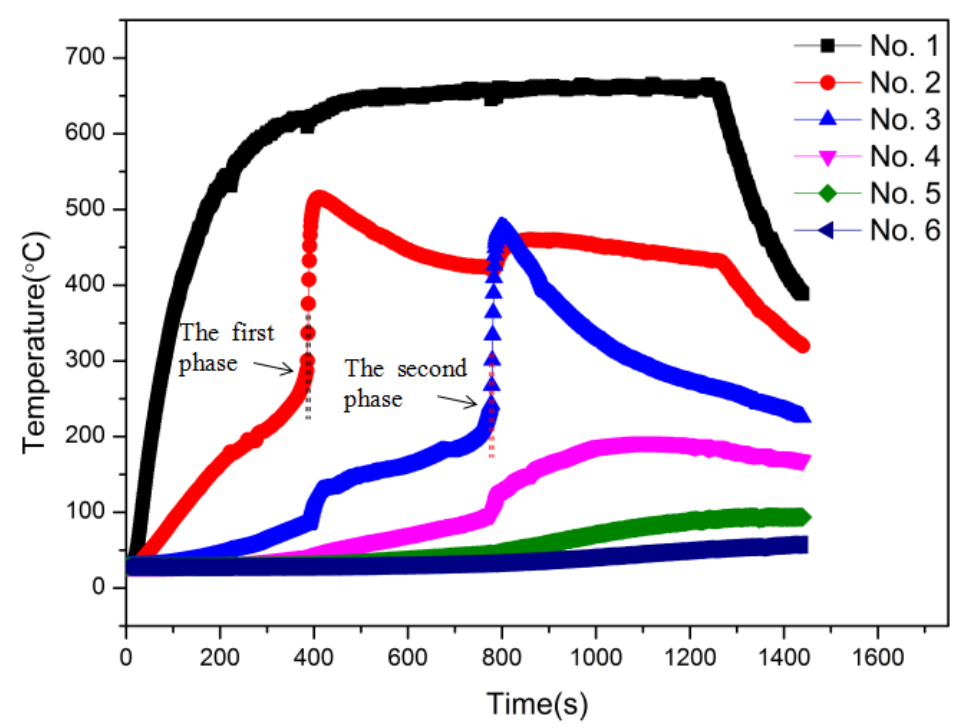

(b)

Figure 13. The typical surface temperature curves of batteries in linear modules: (a) with discharging treatment; (b) without discharging treatment. 


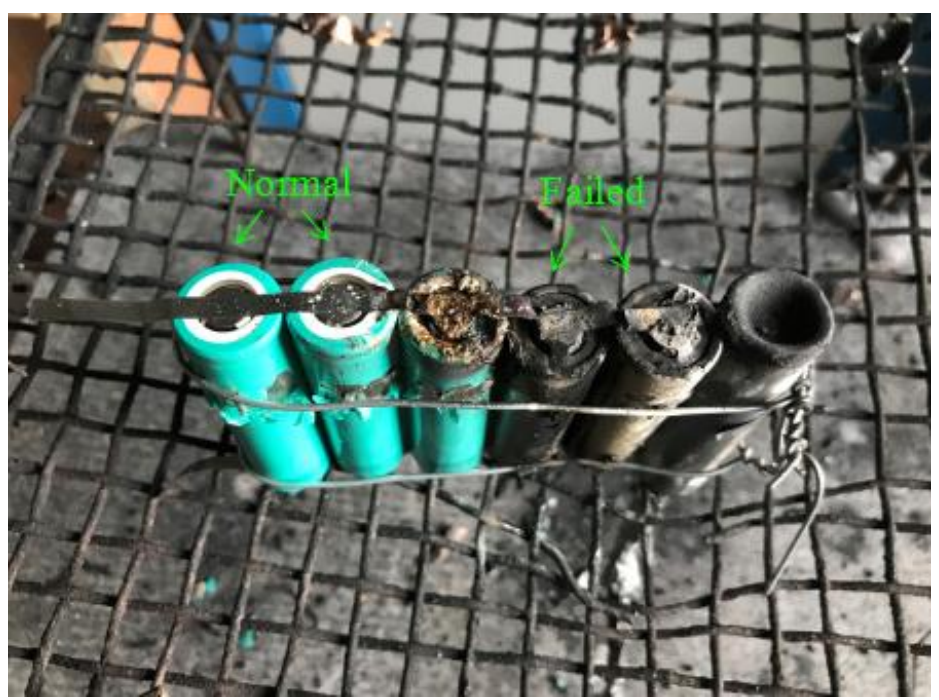

Figure 14. The photograph of linear module after test.

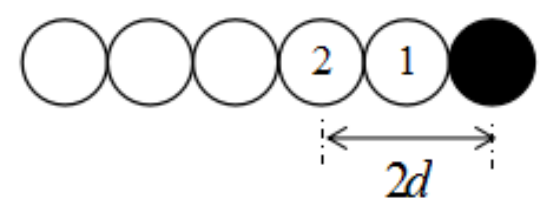

Figure 15. The domino effect of thermal failure propagation in linear module.

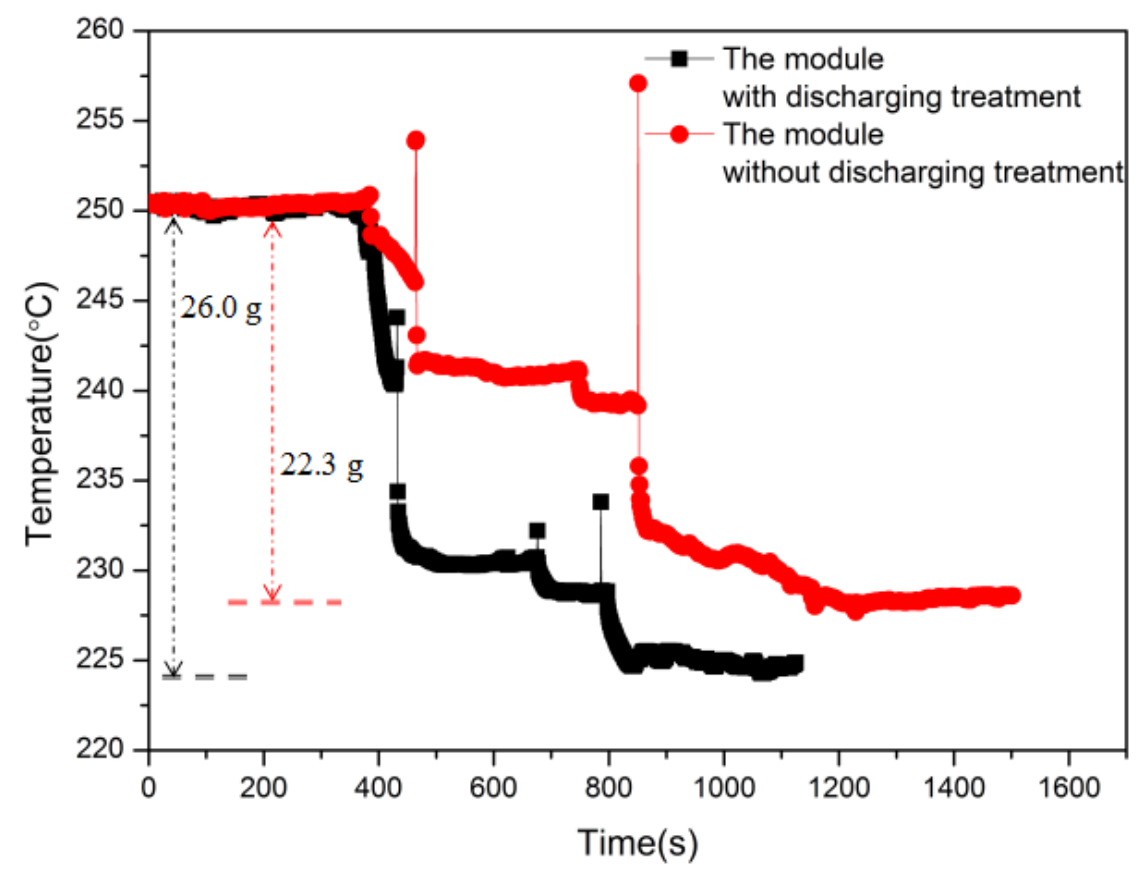

Figure 16. The typical curves of mass loss for linear modules in tests.

Table 5. The detailed information of linear modules in tests.

\begin{tabular}{cccccc}
\hline No. & $\begin{array}{c}\text { With Discharging } \\
\text { Treatment }\end{array}$ & $\begin{array}{c}\text { Time to the First } \\
\text { Phase (s) }\end{array}$ & $\begin{array}{c}\text { Time to the } \\
\text { Second Phase (s) }\end{array}$ & $\begin{array}{c}\text { Propagation } \\
\text { Speed (mm/s) }\end{array}$ & Mass Loss (g) \\
\hline 1 & Yes & 372 & 681 & 0.053 & 26.0 \\
2 & No & 385 & 777 & 0.046 & 22.3 \\
\hline
\end{tabular}




\subsection{Hexagon Module}

The surface temperature variations of batteries in the hexagon modules during tests are drawn in Figure 17. The domino effect in the failure propagation is displayed in Figure 18, which consisted of two phases of failure. The three batteries near the heater composed the first phase and the others were the second. It was an arcuated propagation centered on the heater. For the module with discharging treatment, the thermal failures took place at $412 \mathrm{~s}$ and $504 \mathrm{~s}$, respectively, compared to that of the module without discharging treatment, at $470 \mathrm{~s}$ and $587 \mathrm{~s}$, respectively. In the hexagon module, the propagation distance was two times the battery diameter, $36 \mathrm{~mm}$. In other words, the propagation speed of hexagon modules was $0.071 \mathrm{~mm} / \mathrm{s}$ and $0.061 \mathrm{~mm} / \mathrm{s}$, corresponding to the two modules, respectively. Additionally, Figure 19 exhibits the typical curves of mass loss for hexagon modules in tests and the specifics are further listed in Table 6.

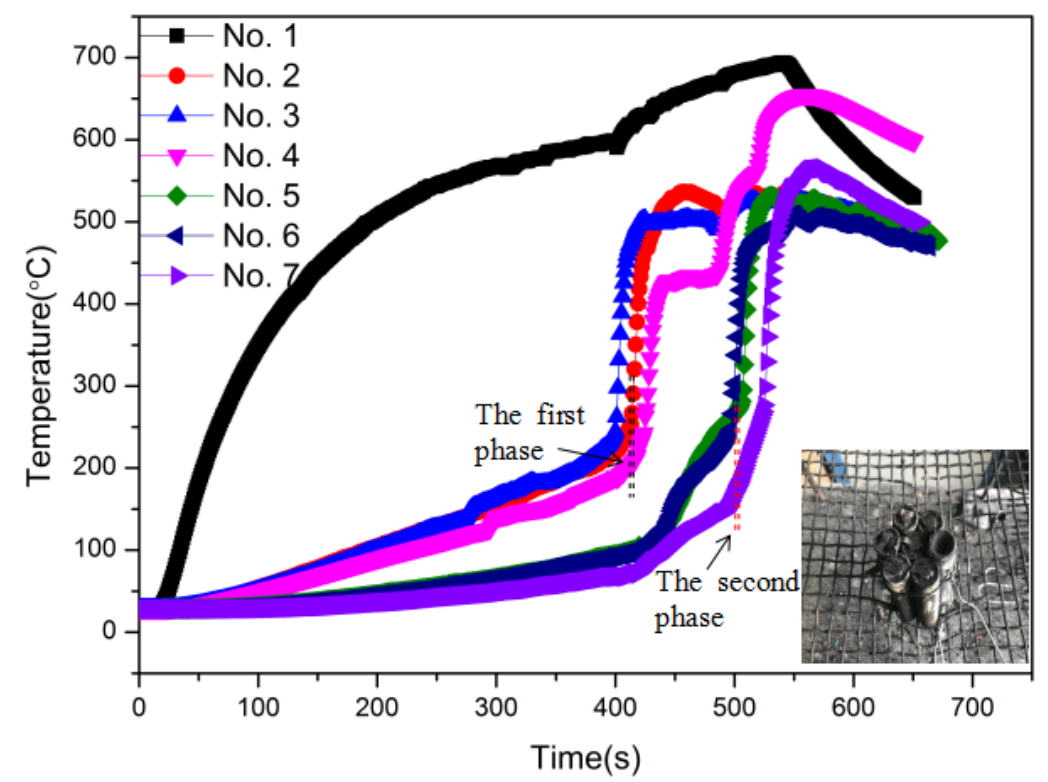

(a)

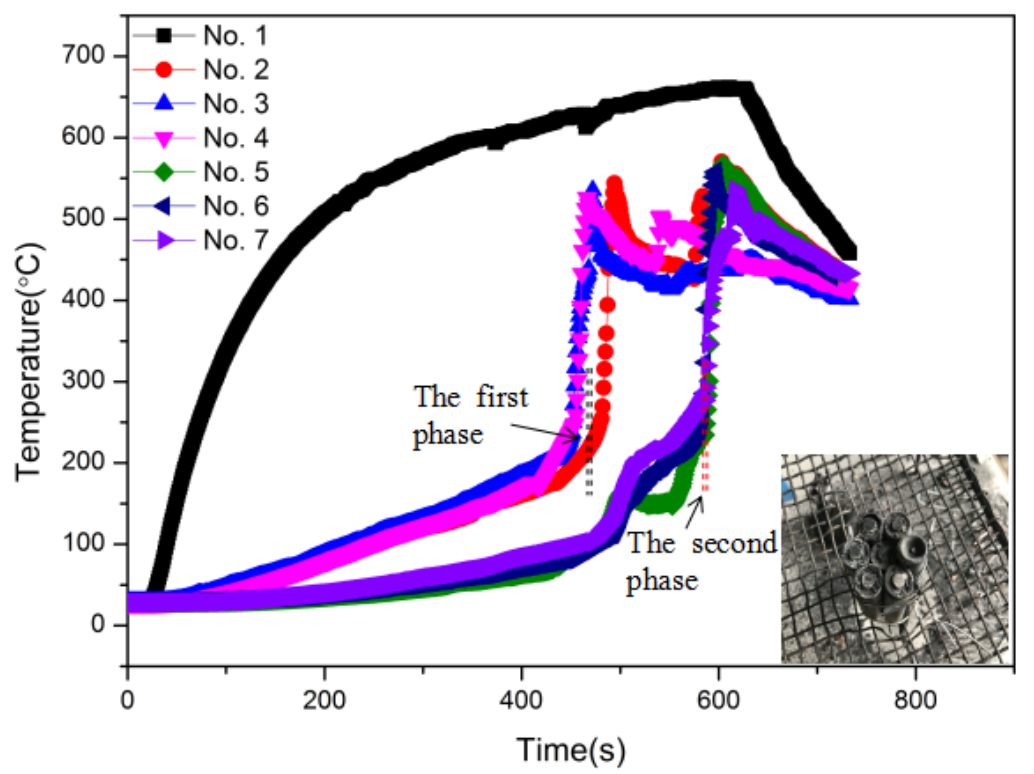

(b)

Figure 17. The typical surface temperature curves of batteries in hexagon modules: (a) with discharging treatment; (b) without discharging treatment. 


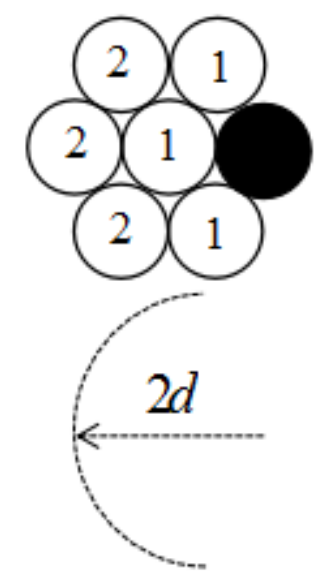

Figure 18. The domino effect of thermal failure propagation in hexagon module.

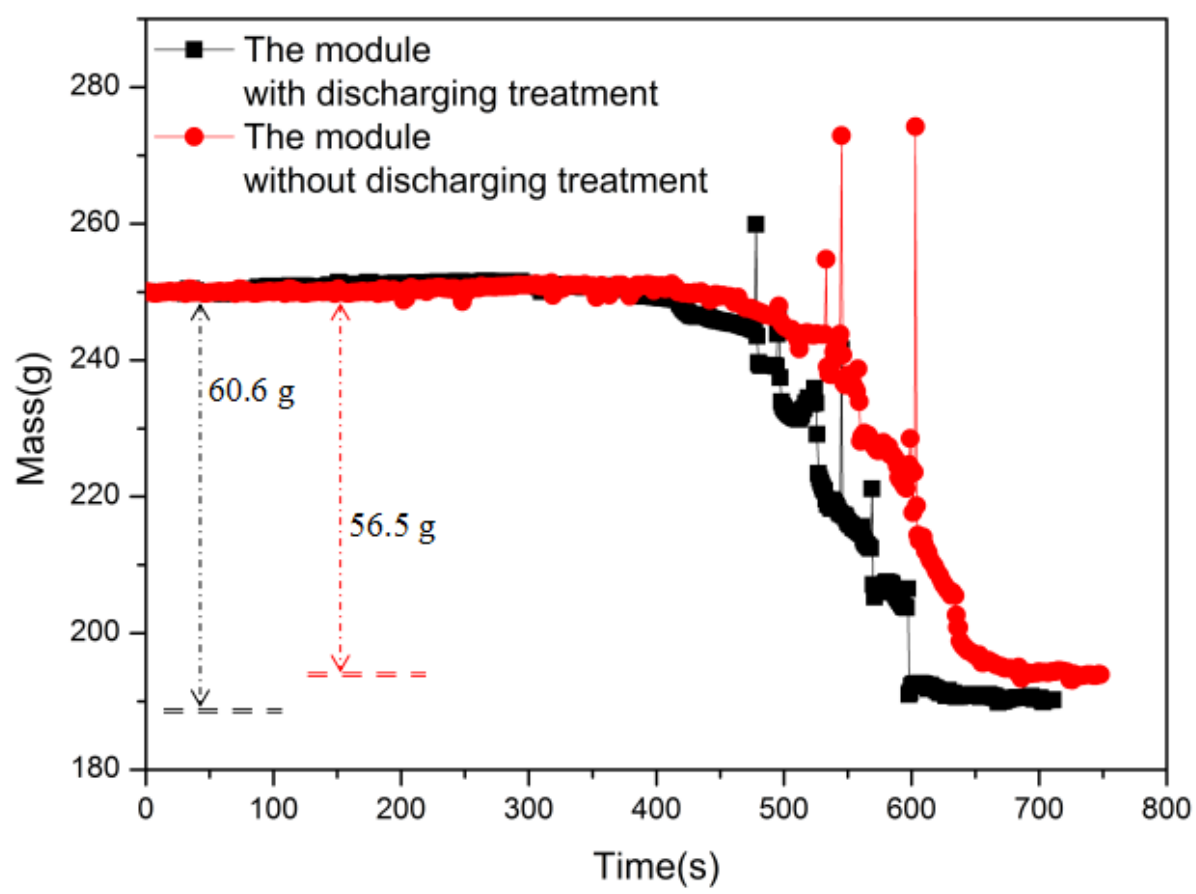

Figure 19. The typical curves of mass loss for hexagon modules.

Table 6. The detailed information of hexagon modules.

\begin{tabular}{cccccc}
\hline No. & $\begin{array}{c}\text { With Discharging } \\
\text { Treatment }\end{array}$ & $\begin{array}{c}\text { Time to the } \\
\text { First Phase (s) }\end{array}$ & $\begin{array}{c}\text { Time to the } \\
\text { Second Phase (s) }\end{array}$ & $\begin{array}{c}\text { Propagation } \\
\text { Speed (mm/s) }\end{array}$ & Mass Loss (g) \\
\hline 1 & Yes & 412 & 504 & 0.071 & 60.6 \\
2 & No & 470 & 587 & 0.061 & 56.5 \\
\hline
\end{tabular}

\subsection{Square Module}

Figure 20 plots the typical surface temperature curves of batteries in square modules and the domino effect in the thermal failure propagation is further displayed in Figure 21. It exhibits three phases of failure during the propagation in square modules. The two batteries close to the heater failed at first, followed by the three batteries in the middle of the module, and the three batteries at the corner failed last. For the module with discharging treatment, the thermal failure appeared at $391 \mathrm{~s}, 612 \mathrm{~s}$, and $735 \mathrm{~s}$, respectively, and for the module without discharging treatment, the time to thermal failure 
was $412 \mathrm{~s}, 636 \mathrm{~s}$, and $863 \mathrm{~s}$, respectively. In the square module, it had a propagation distance of $50.9 \mathrm{~mm}$. Hence, the two modules had a propagation speed of $0.069 \mathrm{~mm} / \mathrm{s}$ and $0.059 \mathrm{~mm} / \mathrm{s}$, respectively.

Finally, the mass loss process of square modules during tests was shown in Figure 22. Consistent to the findings above, the square module with discharging treatment exhibited an earlier mass loss and it lost a mass of $84.0 \mathrm{~g}$, which was relatively larger than that of another module, $83.0 \mathrm{~g}$. The detailed information is seen in Table 7.

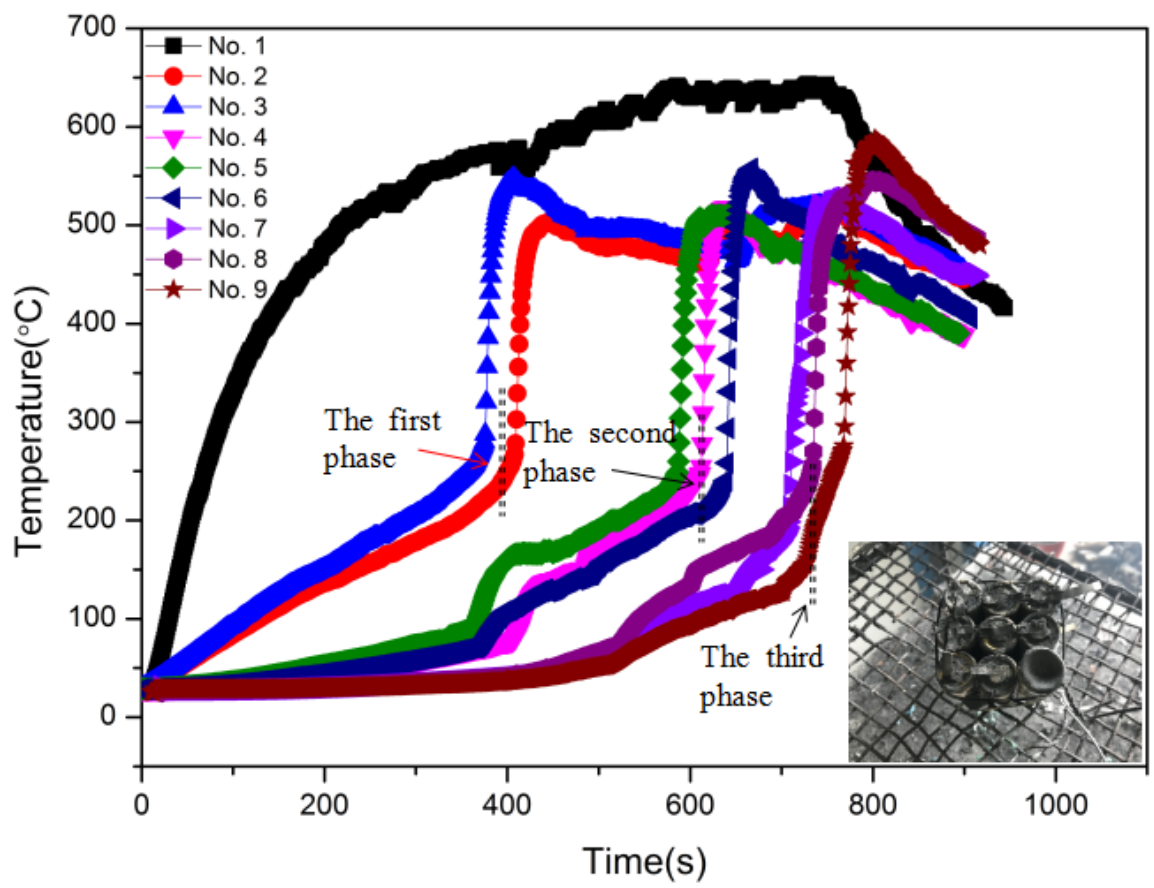

(a)

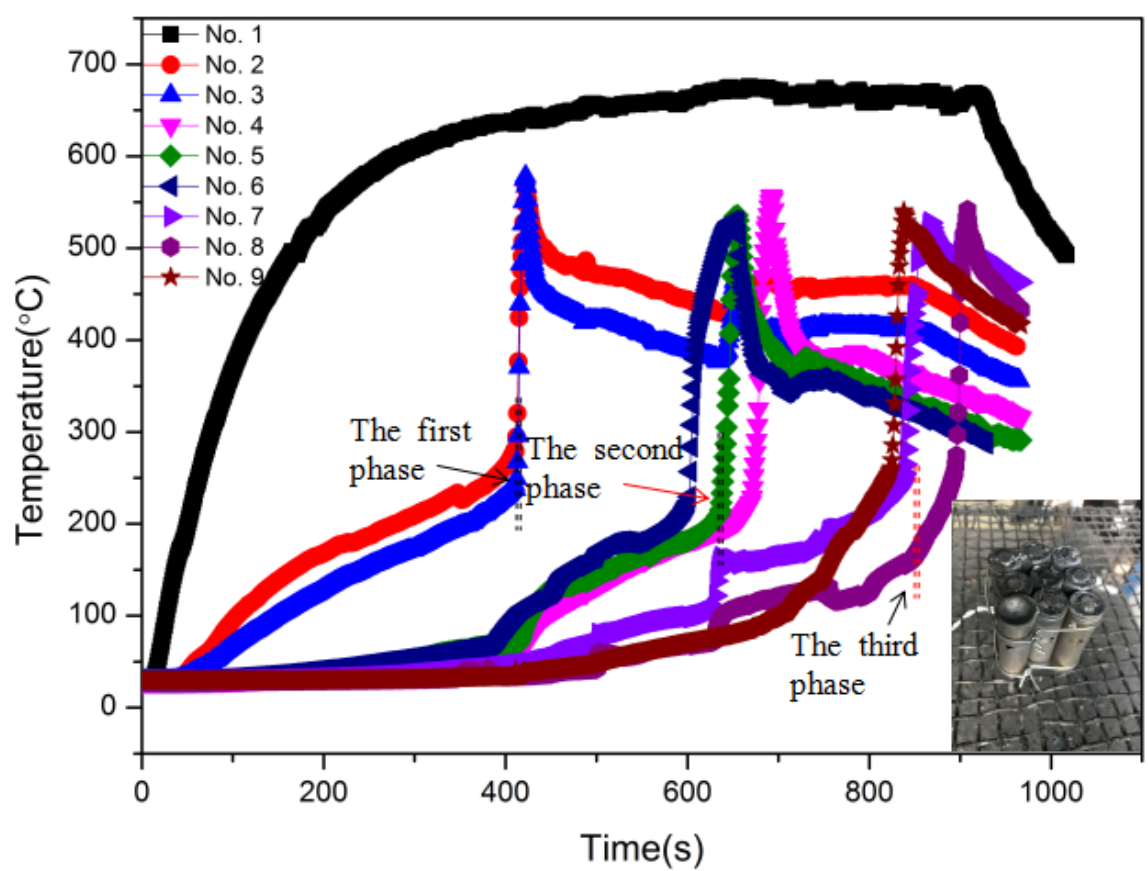

(b)

Figure 20. The typical surface temperature curves of batteries in square modules: (a) with discharging treatment; (b) without discharging treatment. 


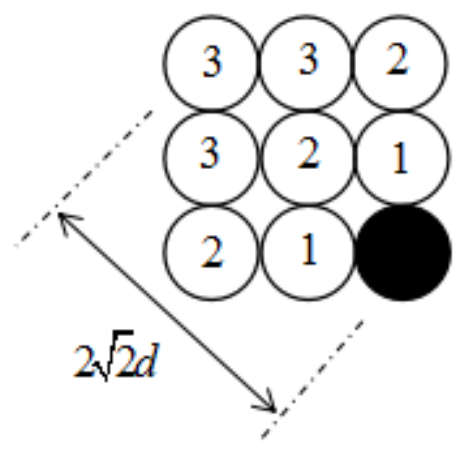

Figure 21. The domino effect of thermal failure propagation in square module.

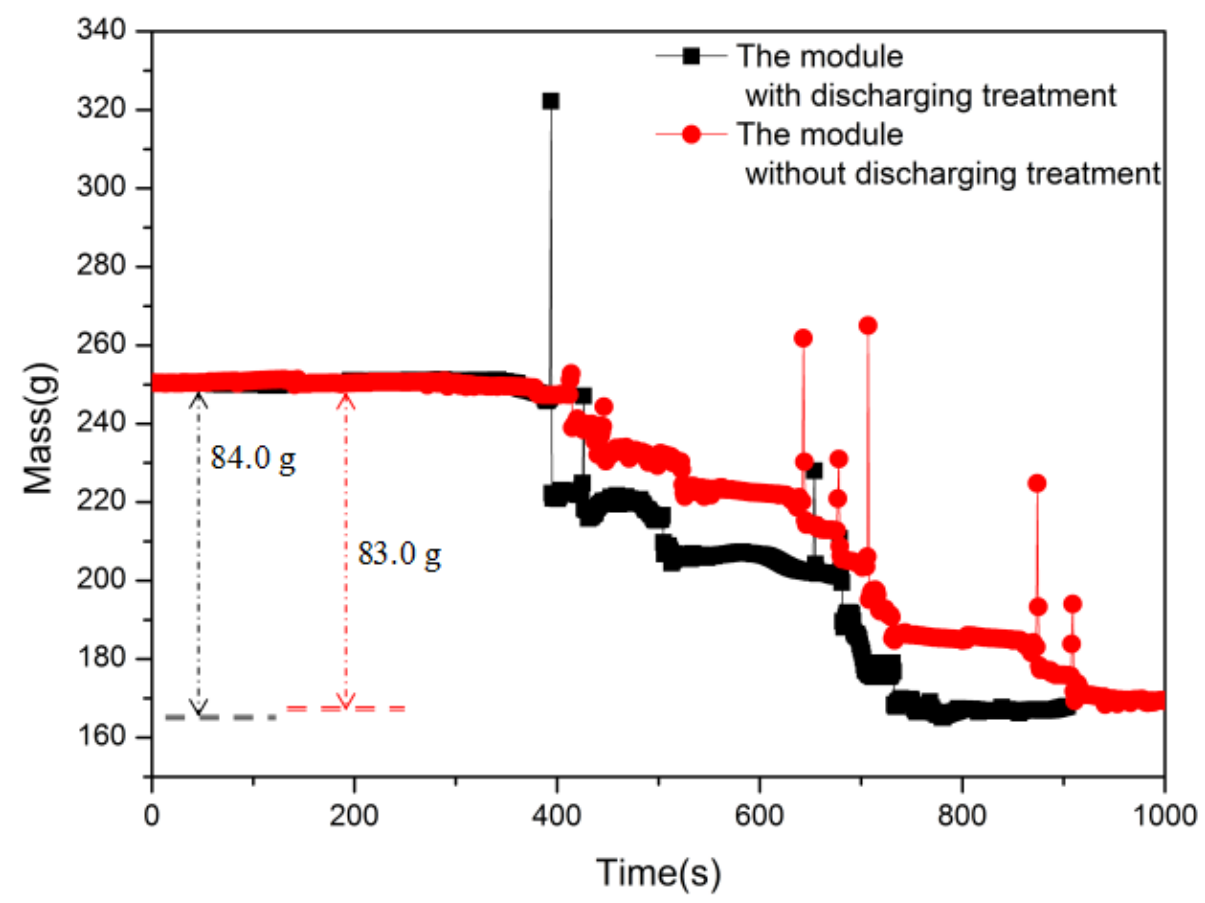

Figure 22. The typical curves of mass loss for square modules in tests.

Table 7. The detailed information of square modules in tests.

\begin{tabular}{ccccccc}
\hline No. & $\begin{array}{c}\text { With Discharging } \\
\text { Treatment }\end{array}$ & $\begin{array}{c}\text { Time to the } \\
\text { First Phase (s) }\end{array}$ & $\begin{array}{c}\text { Time to the } \\
\text { Second Phase (s) }\end{array}$ & $\begin{array}{c}\text { Time to the } \\
\text { Third Phase (s) }\end{array}$ & $\begin{array}{c}\text { Propagation } \\
\text { Speed (mm/s) }\end{array}$ & Mass Loss (g) \\
\hline 1 & Yes & 391 & 612 & 735 & 0.069 & 84.0 \\
2 & No & 412 & 636 & 863 & 0.059 & 83.0 \\
\hline
\end{tabular}

\subsection{Discussion}

The times to each phase of failure for modules with various shapes (triangle, rectangle, parallelogram, line, hexagon, and square) are summarized in Figure 23, where (1) and (2) represents the module with and without discharging treatment, respectively. As can be seen, most of the times to the first phase of failure floated around $400 \mathrm{~s}$. Among them, the hexagon module without discharging treatment had the largest value of time to failure. It implied that failure propagated to the batteries in the first phase of hexagon modules took the longest time. It may be explained by the larger number of batteries in the first phase of hexagon modules, which delayed the propagation. As for the second phase of failure, most of them floated in the range of 500-650 s. Obviously, it was much faster when failure propagated from the first phase to the second phase than between the heater and the first 
phase. It was caused by the larger amount of heat from the failed batteries. According to the results of previous experiments [29], a single 18650 battery had an average heat-output power of $600 \mathrm{~W}$ during the thermal runaway process which was relatively higher than that of the heater. In the second phase of failure, the propagation exhibited the slowest speed in the linear module without discharging treatment. It was due to the relatively smaller contact area in the linear module which restricted the failure propagation. It even lagged behind the third phase of failure in the rectangle module and parallelogram module. Finally, only the rectangle module, parallelogram module, and square module had the third phase and it took a longer time when thermal failure propagated to the outermost phase of battery in the square module. It resulted from the longer propagation distance in the square module, $50.9 \mathrm{~mm}$ compared to that of the others, $36 \mathrm{~mm}$ and $46.8 \mathrm{~mm}$.

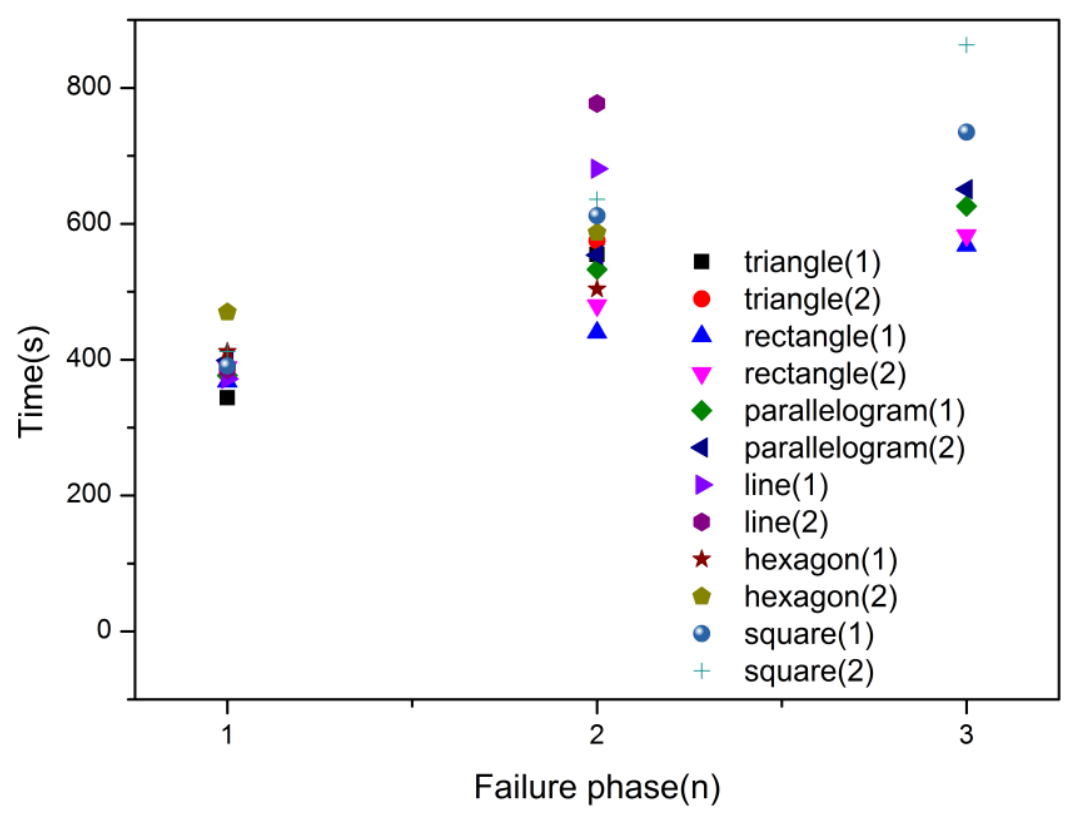

Figure 23. Time to each phase of failure for modules with various shapes.

In addition, the propagation speeds of the modules described above are plotted in Figure 24, where the numbering $1,2,3,4,5$, and 6 represents the triangle module, rectangle module, parallelogram module, line module, hexagon module, and square module, respectively. It could be found that the failure propagation in the parallelogram module was the worst due to the largest propagation speed it exhibited. Conversely, the triangular module and the linear module presented much better safety, as their propagation speeds were smaller than the others. After combining with the space utilization as displayed in Figure 25, the triangular module may be the best choice of battery module with a lower failure propagation hazard and a higher space utilization.

Finally, for the real battery packs or modules with BMS/cooling systems, the thermal failure propagation would not be so severe and it could be restricted somewhat under the effect of the system. Compared to the simplified modules, the discharging treatment would be suspended earlier by the BMS once the temperature of the module increased above the threshold. Nevertheless, the propagation characteristics might be homologous after the failure of the BMS/cooling system and the domino phenomenon also existed. In summary, the information in this paper may be of interest from a safety design perspective and the related work in the real battery modules shall be conducted to meet the practice in the future. 


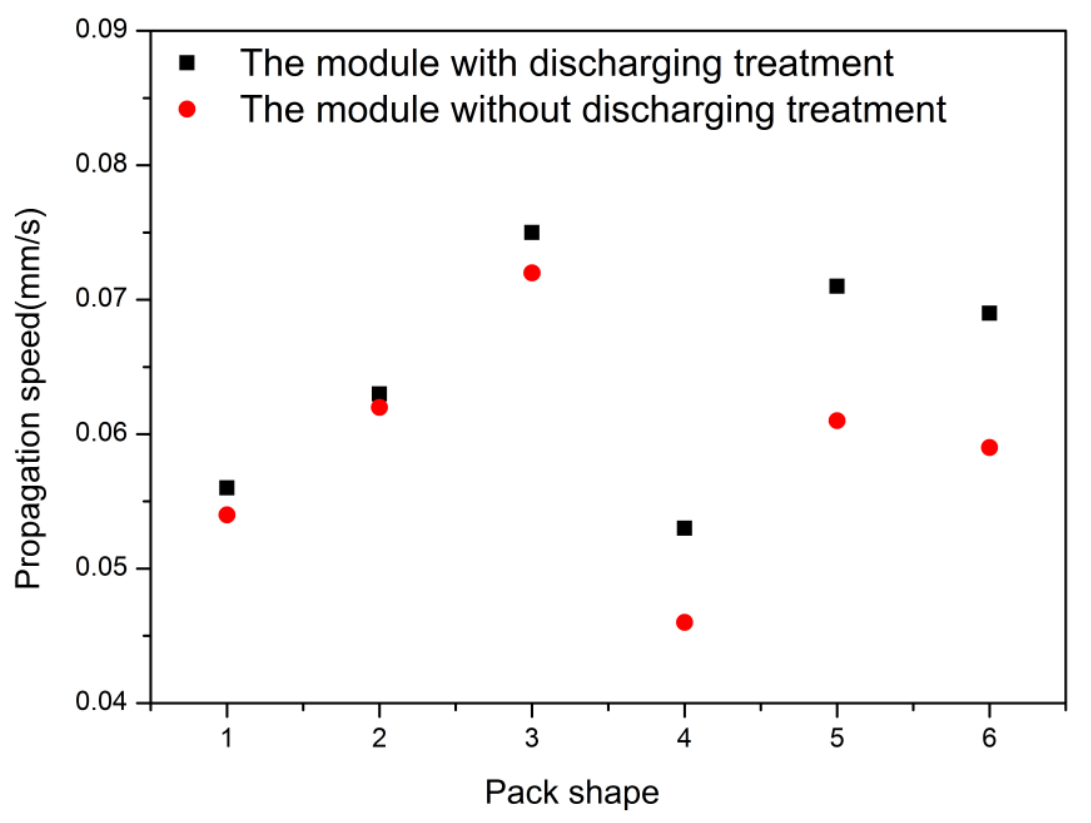

Figure 24. The propagation speeds of modules with various shapes.
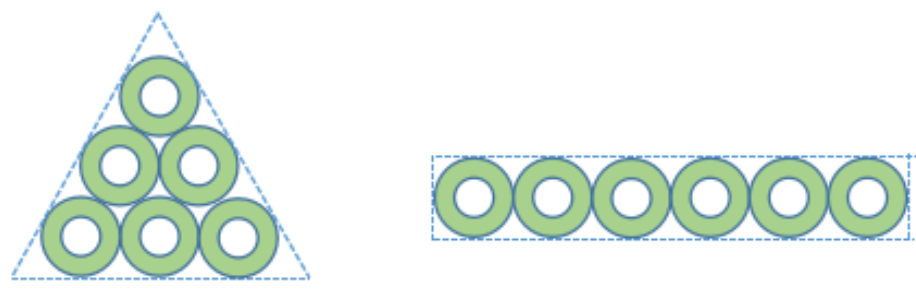

$$
\mathrm{S}_{1}=1795 \mathrm{~mm}^{2}<\mathrm{S}_{2}=1944 \mathrm{~mm}^{2}
$$

Figure 25. The space occupancy of triangular module and linear module.

\section{Conclusions}

Aiming at having a better understanding of the thermal failure propagation of battery modules, this work carried out two groups of experiments to investigate the influence of discharging treatment on the thermal failure propagation in battery modules with various shapes, including triangle, rectangle, parallelogram, line, hexagon, and square. Specific information, such as experimental photograph, battery surface temperature, thermal runaway time, propagation speed, and mass loss, was analyzed.

According to the results, the evident domino effect in the thermal failure propagation of battery modules can be found. The failure propagation process can be divided into several phases and failure propagates to the next phase of batteries through the former phase. The number of phases varied with the shape of module and it exhibited two phases, three phases, three phases, two phases, two phases, and three phases, respectively, corresponding to the modules listed before. Based on the results it revealed, the module with discharging treatment when it was heated behaved with an earlier thermal failure, a quicker failure propagation, and a larger mass loss compared to the results of modules without discharging treatment. It indicates that discharging treatment will aggravate the thermal failure propagation of battery modules, namely, battery modules under work possess a higher hazard once failure occurs. Besides that, it can be seen that the triangular module and the linear module presented much better safety, and their propagation speeds were smaller than the others. Combined with the results of space utilization, it is revealed that the triangular module may be the best choice of battery module due to its lower failure propagation hazard and higher space utilization. 
Author Contributions: D.O. wrote this paper; J.L., M.C., J.W. and J.W. revised it.

Funding: This research received no external funding.

Acknowledgments: This work was supported by the National Key R\&D Program of China (2016YFC0802500) and the Open Foundation of State Key Laboratory of Fire Science (No. HZ2016-KF13).

Conflicts of Interest: The authors declare no conflict of interest.

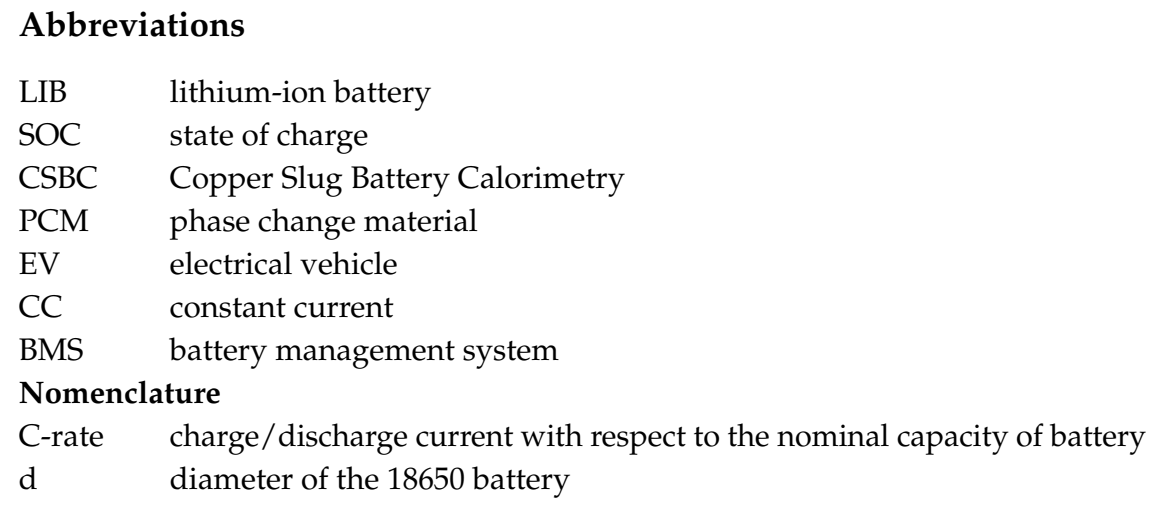

\section{References}

1. Azizi, Y.; Sadrameli, S.M. Thermal management of a $\mathrm{LiFePO}_{4}$ battery pack at high temperature environment using a composite of phase change materials and aluminum wire mesh plates. Energy Convers. Manag. 2016, 128, 294-302. [CrossRef]

2. Wu, W.; Yang, X.; Zhang, G. Experimental investigation on the thermal performance of heat pipe-assisted phase change material based battery thermal management system. Energy Convers. Manag. 2017, 138, 486-492. [CrossRef]

3. Maleki, H.; Howard, J.N. Effects of overdischarge on performance and thermal stability of a Li-ion cell. J. Power Sources 2006, 160, 1395-1402. [CrossRef]

4. Doughty, D.H.; Roth, E.P. A general discussion of Li ion battery safety. Electrochem. Soc. Interface 2012, 21, 37-44. [CrossRef]

5. Belov, D.; Yang, M.H. Failure mechanism of Li-ion battery at overcharge conditions. J. Solid State Electrochem. 2008, 12, 885-894. [CrossRef]

6. Larsson, F.; Andersson, P.; Blomqvist, P. Characteristics of lithium-ion batteries during fire tests. J. Power Sources 2014, 271, 414-420. [CrossRef]

7. Ribie're, P.; Grugeon, S.; Morcrette, M.; Boyanov, S.; Laruelle, S.; Marlair, G. Investigation on the fire-induced hazards of Li-ion battery cells by fire calorimetry. Energy Environ. Sci. 2012, 5, 5271-5280. [CrossRef]

8. Ping, P.; Wang, Q.S.; Huang, P.F. Study of the fire behavior of high-energy lithium-ion batteries with full-scale burning test. J. Power Sources 2015, 285, 80-89. [CrossRef]

9. Chen, M.; Liu, J.; He, Y. Study of the fire hazards of lithium-ion batteries at different pressures. Appl. Therm. Eng. 2017, 125, 1061-1074. [CrossRef]

10. Liu, X.; Stoliarov, S.I.; Denlinger, M. Comprehensive calorimetry of the thermally-induced failure of a lithium ion battery. J. Power Sources 2015, 280, 516-525. [CrossRef]

11. Hinkkanen, S. A Hardware-In-the-Loop Simulator of an Electric Bus Charging Station: The Design of the System and Preliminary Battery Simulations. Master's Thesis, Turku University of Applied Sciences, Turku, Finland, 2018.

12. Panchal, S. Impact of Vehicle Charge and Discharge Cycles on the Thermal Characteristics of Lithium-ion Batteries. Ph.D. Thesis, University of Waterloo, Waterloo, ON, Canada, 2014.

13. Saw, L.H.; Ye, Y.; Tay, A.A.O. Computational fluid dynamic and thermal analysis of Lithium-ion battery pack with air cooling. Appl. Energy 2016, 177, 783-792. [CrossRef]

14. Huo, Y.; Rao, Z.; Liu, X. Investigation of power battery thermal management by using mini-channel cold plate. Energy Convers. Manag. 2015, 89, 387-395. [CrossRef]

15. Yan, J.; Li, K.; Chen, H. Experimental study on the application of phase change material in the dynamic cycling of battery pack system. Energy Convers. Manag. 2016, 128, 12-19. [CrossRef] 
16. Li, K.; Yan, J.; Chen, H. Water cooling based strategy for lithium ion battery pack dynamic cycling for thermal management system. Appl. Therm. Eng. 2018, 132, 575-585. [CrossRef]

17. Zhao, J.; Rao, Z.; Huo, Y. Thermal management of cylindrical power battery module for extending the life of new energy electric vehicles. Appl. Therm. Eng. 2015, 85, 33-43. [CrossRef]

18. Wang, Z.; Li, X.; Zhang, G. Experimental study of a passive thermal management system for three types of battery using copper foam saturated with phase change materials. RSC Adv. 2017, 7, 27441-27448. [CrossRef]

19. Al-Zareer, M.; Dincer, I.; Rosen, M.A. Novel thermal management system using boiling cooling for high-powered lithium-ion battery packs for hybrid electric vehicles. J. Power Sources 2017, 363, 291-303. [CrossRef]

20. Feng, X.; Lu, L.; Ouyang, M. A 3D thermal runaway propagation model for a large format lithium ion battery module. Energy 2016, 115, 194-208. [CrossRef]

21. Lamb, J.; Orendorff, C.J.; Steele, L.A.M. Failure propagation in multi-cell lithium ion batteries. J. Power Sources 2015, 283, 517-523. [CrossRef]

22. Coman, P.T.; Darcy, E.C.; Veje, C.T. Numerical analysis of heat propagation in a battery pack using a novel technology for triggering thermal runaway. Appl. Energy 2017, 203, 189-200. [CrossRef]

23. Lopez, C.F.; Jeevarajan, J.A.; Mukherjee, P.P. Experimental analysis of thermal runaway and propagation in lithium-ion battery modules. J. Electrochem. Soc. 2015, 162, A1905-A1915. [CrossRef]

24. Wilke, S.; Schweitzer, B.; Khateeb, S. Preventing thermal runaway propagation in lithium ion battery packs using a phase change composite material: An experimental study. J. Power Sources 2017, 340, 51-59. [CrossRef]

25. Feng, X.; Sun, J.; Ouyang, M. Characterization of penetration induced thermal runaway propagation process within a large format lithium ion battery module. J. Power Sources 2015, 275, 261-273. [CrossRef]

26. Larsson, F.; Anderson, J.; Andersson, P. Thermal modelling of cell-to-cell fire propagation and cascading thermal runaway failure effects for lithium-ion battery cells and modules using fire walls. J. Electrochem. Soc. 2016, 163, A2854-A2865. [CrossRef]

27. Spotnitz, R.M.; Weaver, J.; Yeduvaka, G. Simulation of abuse tolerance of lithium-ion battery packs. J. Power Sources 2007, 163, 1080-1086. [CrossRef]

28. Ouyang, D.; He, Y.; Chen, M. Experimental study on the thermal behaviors of lithium-ion batteries under discharge and overcharge conditions. J. Therm. Anal. Calorim. 2018, 132, 65-75. [CrossRef]

29. Chen, M.; Zhou, D.; Chen, X. Investigation on the thermal hazards of 18,650 lithium ion batteries by fire calorimeter. J. Therm. Anal. Calorim. 2015, 122, 755-763. [CrossRef] 